\title{
Photoinduced charge separation in the carbon nano-onion $\mathbf{C}_{60} @ \mathbf{C}_{240}$
}

\author{
Alexander A. Voityuk ${ }^{1,2 *}$ and Miquel Solà ${ }^{*}$ \\ ${ }^{1}$ Institució Catalana de Recerca i Estudis Avançats (ICREA), Barcelona 08010, Spain \\ ${ }^{2}$ Institut de Química Computacional i Catàlisi (IQCC) and Departament de Química, Campus de \\ Montilivi, 17071 Girona, Catalonia, Spain. \\ E-mail: alexander.voityuk@icrea.cat; miquel.sola@udg.edu
}

\begin{abstract}
The double-shell fullerene $\mathrm{C}_{60} @ \mathrm{C}_{240}$ formed by inclusion of $\mathrm{C}_{60}$ into $\mathrm{C}_{240}$ is the smallest stable carbon nano-onion. In the paper, we analyze in detail the character of excited states of $\mathbf{C}_{60} @ \mathrm{C}_{240}$ in terms of exciton localization and charge transfer between the inner and outer shells. The unique structure of the buckyonion leads to a large electrostatic stabilization of charge-separated (CS) states in the $\mathrm{C}_{60} @ \mathrm{C}_{240}$. As a result, the $\mathrm{CS}$ states $\mathrm{C}_{60}{ }^{+} @ \mathrm{C}_{240}{ }^{-}$lie in the same region of the electronic spectrum (2.4-2.6 eV) as strongly absorbing locally excited states, and therefore, can be effectively populated. The CS states $\mathrm{C}_{60}{ }^{-} @ \mathrm{C}_{240}{ }^{+}$are found to be by $0.5 \mathrm{eV}$ higher in energy than the states $\mathrm{C}_{60}{ }^{+} @ \mathrm{C}_{240}$. Unlike the situation observed in donor-acceptor systems, the energy of the CS states in $\mathrm{C}_{60} @ \mathrm{C}_{240}$ does not practically depend on the environment polarity. This leads to exceptionally small reorganization energies for electron transfer between the shells. Electronic couplings for photoinduced charge separation and charge recombination processes are calculated. The absolute rate of the formation of the CS states $\mathrm{C}_{60}{ }^{+} @ \mathrm{C}_{240}{ }^{-}$is estimated at $\sim 4 \mathrm{ps}^{-1}$. The electronic features found in $\mathrm{C}_{60} @ \mathrm{C}_{240}$ are likely to be shared by other carbon nano-onions.
\end{abstract}




\section{Introduction}

Carbon nano-onions (CNOs), also known as multi-shell fullerenes, hyperfullerenes or buckyonions, are formed by several concentric shells of carbon atoms in a structure resembling a nesting Russian doll. ${ }^{1-3}$ From vacuum deposited amorphous carbon films, Iijima observed CNOs for the first time in $1980 .{ }^{4}$ He presented electron micrographs of small spherical particles of graphitized carbon whose sizes varied in between 30-70 A in diameter. Five years later, $\mathrm{C}_{60}$ was discovered by Kroto, Smalley, and Curl. ${ }^{5}$ In 1987, Iijima realized that the inner most shell of the CNOs he observed in 1980 has a diameter of $8 \AA$ and, therefore, it could perfectly be $\mathrm{C}_{60} .{ }^{6}$ In 1992 , Ugarte $^{7}$ obtained CNOs by intense irradiation of carbon soot. Nowadays, there are several procedures that can be used to produce CNOs at relatively large scale. ${ }^{1,3,8-9}$ A number of various functionalization reactions of CNOs have been developed. In fact, the first covalent functionalized $\mathrm{CNO}$ was obtained by a 1,3-dipolar addition of azomethine ylide in $2003 .{ }^{10} \mathrm{CNO}$ s have already been proved to offer a variety of potential applications. Among them, we can mention their application as electrode materials in capacitors, ${ }^{11}$ anode materials in lithium-ion batteries, ${ }^{8}$ catalyst support in fuel cells, ${ }^{12}$ solid lubrication, ${ }^{13}$ heterogeneous catalysis, ${ }^{14}$ or electro-optical devices. ${ }^{15}$

The first observation of double- and triple-shell CNOs was reported in $2000 .{ }^{16}$ The doubleshell $\mathrm{C}_{60} @ \mathrm{C}_{240}$ and $\mathrm{C}_{240} @ \mathrm{C}_{560}$ and triple-shell $\mathrm{C}_{60} @ \mathrm{C}_{240} @ \mathrm{C}_{560}$ fullerenes were found in the products of the high temperature laser pyrolysis. Because of its relatively small size, $\mathrm{C}_{60} @ \mathrm{C}_{240}$ has been studied theoretically by several groups. At the density functional theory (DFT) level, it has been found that the van der Waals interaction energy between $\mathrm{C}_{60}$ and $\mathrm{C}_{240}$ in $\mathrm{C}_{60} @ \mathrm{C}_{240}$ is about -150 to $-185 \mathrm{kcal} / \mathrm{mol} .{ }^{17-19}$ The global minimum of $\mathrm{C}_{60} @ \mathrm{C}_{240}$ has $\mathrm{D}_{5 \mathrm{~d}}$ symmetry, although rotation of $\mathrm{C}_{60}$ inside $\mathrm{C}_{240}$ is almost free with energy barriers of about $1 \mathrm{kcal} / \mathrm{mol}$, the $\mathrm{I}_{\mathrm{h}}$ structure depicted in Figure 1 being almost isoenergetic with the $\mathrm{D}_{5 \mathrm{~d}}$ one. Geometry relaxation of $\mathrm{C}_{60}$ and $\mathrm{C}_{240}$ in $\mathrm{C}_{60} @ \mathrm{C}_{240}$ was found to be negligible, ${ }^{19} \mathrm{C}_{60}$ being slightly expanded inside $\mathrm{C}_{240}$, while $\mathrm{C}_{240}$ somewhat shrunk. ${ }^{18}$ Moreover, because $\mathrm{C}_{60}, \mathrm{C}_{240}$, and $\mathrm{C}_{60} @ \mathrm{C}_{240}$ are of the same symmetry $\left(\mathrm{I}_{\mathrm{h}}\right)$, the electronic structure of these molecules is similar. In particular, their HOMO (highest occupied molecular orbital) is five-fold degenerated whereas the LUMO (lowest unoccupied molecular orbital) has three-fold degeneracy. In fact, it was found computationally that $\mathrm{C}_{60} @ \mathrm{C}_{240}$ shows an $\mathrm{UV}$-Vis spectrum that is the overlap of the two spectra of $\mathrm{C}_{60}$ and $\mathrm{C}_{240}{ }^{18}$ In addition, the vibrational modes of $\mathrm{C}_{60}$ and $\mathrm{C}_{240}$ in $\mathrm{C}_{60} @ \mathrm{C}_{240}$ are clearly recognizable, with small shifts that reflect the small geometrical deformation of $\mathrm{C}_{60}$ and $\mathrm{C}_{240} .{ }^{18}$ It is worth noting that the reduction in the $\mathrm{C}_{60}$ polarizability after inclusion in $\mathrm{C}_{240}$ was found to be about $75 \% .{ }^{20-21}$ Moreover, there is a charge transfer of about 0.7 electrons from $\mathrm{C}_{60}$ to $\mathrm{C}_{240},{ }^{19}$ as expected from the higher electron affinity of $\mathrm{C}_{240} .{ }^{22-23}$ Interestingly, it was found that when an external electric field is applied, the outer $\mathrm{C}_{240}$ shell almost completely shields the inner $\mathrm{C}_{60}$ cage, and, therefore $\mathrm{C}_{60} @ \mathrm{C}_{240}$

can be considered a near perfect Faraday cage. ${ }^{20-21}$ In fact, the polarizability of $\mathrm{C}_{60} @ \mathrm{C}_{240}$ is essentially due to the outer cage fullerene. ${ }^{21}$ Finally, it was shown that the Xe $4 \mathrm{~d}$ 
photoionization cross section changes significantly when going from $\mathrm{Xe} @ \mathrm{C}_{60}$ and $\mathrm{Xe} @ \mathrm{C}_{240}$ to Xe@ $\mathrm{C}_{60} @ \mathrm{C}_{240 .}{ }^{24}$

From the information given above, it is clear that some properties of the fullerenes change significantly while others remain almost unchanged by the formation of two- and multi-shell structures. Being the smallest stable $\mathrm{CNO},{ }^{18} \mathrm{C}_{60} @ \mathrm{C}_{240}$ is a good computational model to study the structural and electronic properties of CNOs. Because of the size of the CNOs, not much is known about the nature of excited states of these species. In the paper, we will perform a detailed analysis of the excited states of $\mathrm{C}_{60} @ \mathrm{C}_{240}$. Note that the excited states of both fullerenes have similar energies and just a small electronic interaction (coupling) of the states leads to exciton delocalization and to mixing of the locally excited (LE) and charge transfer (CT) states. Moreover, CT configurations $\mathrm{C}_{60}{ }^{+} @ \mathrm{C}_{240}{ }^{-}$and $\mathrm{C}_{60}{ }^{-} @ \mathrm{C}_{240}{ }^{+}$may have a similar energy and significantly contribute to excited states of interest. Because of that, a special computational tool is required for quantitative analysis of excited states in $\mathrm{C}_{60} @ \mathrm{C}_{240}$. Our analysis is based on the treatment of the transition electronic density developed in several recent works ${ }^{25-27}$ and used to describe electronic excitations in a number of molecular systems.

In this paper, 100 low-energy excited states of the $\mathrm{C}_{60} @ \mathrm{C}_{240}$ complex are characterized in terms of exciton localization and CT between the inner and outer spheres. In particular, we consider the nature of states responsible for the light absorption with the aim to know whether $\mathrm{C}_{60} @ \mathrm{C}_{240}$ can act as an effective chromophore in dye-sensitized solar cells. We also calculate electron transfer (ET) parameters for the photo-induced charge separation and charge recombination reactions. Marcus theory ${ }^{28}$ is applied to determine the absolute rate for ET between the inner and outer fullerenes. Our results (vide infra) show that i) charge separated (CS) states $\mathrm{C}_{60}{ }^{+} @ \mathrm{C}_{240^{-}}$lie in the same region of the electronic spectrum (2.4-2.6 eV) as locally excited (LE) states responsible for strong light absorption, and therefore, they can be effectively populated; ii) unlike the situation commonly observed for donor-acceptor systems, the energy of the CS states in the $\mathrm{C}_{60} @ \mathrm{C}_{240}$ is practically independent of the environment polarity (because of its concentric structure) resulting in exceptionally small reorganization energies for electron transfer between the shells; and iii) $\mathrm{C}_{60} @ \mathrm{C}_{240}$ is able to absorb sun energy much more efficiently than the free $\mathrm{C}_{60}$ or $\mathrm{C}_{240}$ molecules. We hope that the unique electronic features of $\mathrm{C}_{60} @ \mathrm{C}_{240}$, which are most likely shared by other CNOs, may be exploited in molecular electronics. 


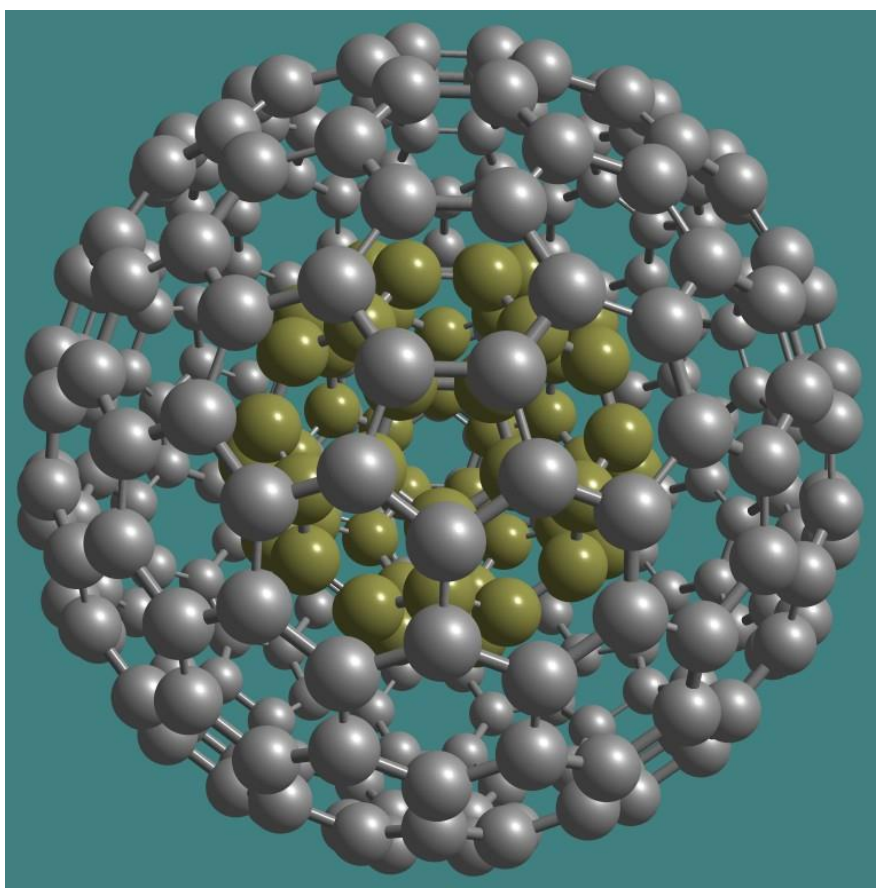

Figure 1. $\mathrm{C}_{60} @ \mathrm{C}_{240}$ complex is composed of two shells $\mathrm{C}_{60}$ and $\mathrm{C}_{240}$ with $I_{h}$ symmetry shown in the olive and gray color, respectively.

\section{Methods}

All quantum mechanical calculations were performed with the Gaussian program. ${ }^{29}$ The ground state geometries of neutral fullerenes $\mathrm{C}_{60}$ and $\mathrm{C}_{240}$ and their radical cation and radical anion species were optimized using the B3LYP/6-31G* scheme. The geometries of the radicals are needed to estimate the reorganization energy of ET between $\mathrm{C}_{60}$ and $\mathrm{C}_{240}$. For comparison, excited states of $\mathrm{C}_{60}$ were calculated using both the TD-DFT (B3LYP and CAMB3LYP with B3LYP with 6-31G* and 6-311+G basis sets) and the semiempirical INDO/S approach..$^{30}$ The calculations of 100 low-energy excited states of $\mathrm{C}_{60} @ \mathrm{C}_{240}$ were performed with INDO/S. All possible singly excited configurations (360000) were accounted for in the configuration interaction scheme. The advantages and limitations of INDO/S as well as its recent applications in material science are considered in the review of Ref. 31.

The energies and oscillator strengths of selected dipole allowed transitions of $\mathrm{C}_{60}$ as well as experimental data are listed in Table 1. Comparison of the computed and observed electronic spectra shows that the INDO/S results for $\mathrm{C}_{60}$ are in better agreement with experiment than the TD-DFT data. A detailed comparison of experimental and computational data for several fullerenes is given in Ref. 24 . Note that $\mathrm{C}_{240}$ has been less extensively characterized due to its lower abundance. Recently, it has been computationally studied at the BLYP/TZP level. ${ }^{18}$ The INDO/S reproduces quantitatively the optical absorption parameters whereas the TDDFT calculations yield less accurate estimates of the transition energies and oscillator 
strengths. Because of that, our analysis of the excited states of $\mathrm{C}_{60} @ \mathrm{C}_{240}$ was done on the basis of the INDO/S calculation. The analysis of the nature of excited states and the calculation of electronic couplings were performed using a local program.

Table 1. Excitation Energies and Oscillator Strengths for Optically Allowed Transitions in $\mathrm{C}_{60}$

\begin{tabular}{lllll}
\hline Method & $\mathrm{h} v, \mathrm{eV}$ & $\mathrm{f}$ & $\mathrm{h} v, \mathrm{eV}$ & $\mathrm{f}$ \\
\hline B3LYP/6-31G* & 3.510 & 0.0105 & 3.954 & 0.156 \\
B3LYP/6-311+G* $^{*}$ & 3.484 & 0.0103 & 3.902 & 0.170 \\
CAM-B3LYP/6-311+G* & 4.320 & 0.247 & 4.691 & 0.101 \\
INDO/S $_{\text {Experiment }}{ }^{\mathrm{a}}$ & 3.214 & 0.011 & 3.846 & 0.386 \\
\hline
\end{tabular}

${ }^{\mathrm{a}}$ Experimental data are taken from Refs. 18, 32.

\section{Analysis of excited states}

The energetic similarities of electronic excitations in $\mathrm{C}_{60}$ and $\mathrm{C}_{240}$ make it difficult to explore even their qualitative nature. The quantitative analysis of exciton delocalization and charge separation was carried out in terms of transition density. ${ }^{26-27}$ Because the INDO/S scheme employs an orthogonal basis set (it means that the overlap matrix is diagonal), a key quantity $\Omega(\mathrm{A}, \mathrm{B})$ used in the analysis of the density distribution between molecules $\mathrm{A}$ and $\mathrm{B}$, is defined as

$$
\begin{aligned}
& \Omega(\mathrm{A}, \mathrm{B})=\frac{1}{2} \sum_{\alpha \in \mathrm{A}, \beta \in \mathrm{B}} \mathrm{P}_{\alpha \beta}^{0 \mathrm{i}} \mathrm{P}_{\alpha \beta}^{0 \mathrm{i}} \\
& \mathrm{X}(\mathrm{A})=\Omega(\mathrm{A}, \mathrm{A}) \\
& \Delta \mathrm{q}=\Omega(\mathrm{A}, \mathrm{B})-\Omega(\mathrm{B}, \mathrm{A})
\end{aligned}
$$

where $\mathbf{P}^{0 i}$ is the transition density matrix for the $\psi_{0} \rightarrow \psi_{i}$ excitation. The extent of exciton localization on the site $\mathrm{A}$ is termed $X(A)$, the electron transfer from site $\mathrm{A}$ to $\mathrm{B}$ and from $\mathrm{B}$ to $\mathrm{A}$ is represented by $\Omega(\mathrm{A}, \mathrm{B})$ and $\Omega(\mathrm{B}, \mathrm{A})$, respectively. The total weight of CT states in $\psi_{\mathrm{i}}$ is equal to $\Omega(\mathrm{A}, \mathrm{B})+\Omega(\mathrm{B}, \mathrm{A})$ whereas the charge separation between sites $\mathrm{A}$ and $\mathrm{B}$ is determined by the difference $\Delta \mathrm{q}$ given by the difference $\Omega(\mathrm{A}, \mathrm{B})-\Omega(\mathrm{B}, \mathrm{A})$.

Solvent effects. The equilibrium solvation energy $\mathrm{E}_{\mathrm{S}}^{\mathrm{eq}}$ in medium with the dielectric constant $\varepsilon$ was estimated using a COSMO-like polarizable continuum model (C-PCM) in monopole approximation 30,33

$$
\mathrm{E}_{\mathrm{S}}^{\mathrm{eq}}(\mathrm{Q}, \varepsilon)=-\frac{1}{2} f(\varepsilon) \mathrm{Q}^{+} \mathrm{DQ}
$$


where the $f(\varepsilon)$ is the dielectric scaling factor, $f(\varepsilon)=\frac{\varepsilon-1}{\varepsilon}, \mathbf{Q}$-the vector of $n$ atomic charges in the molecule, $\mathbf{D}$ is the $n \times n$ symmetric matrix determined by the shape of the boundary surface between solute and solvent; $\mathbf{D}=\mathbf{B}^{+} \mathbf{A}^{-1} \mathbf{B}$, where the $m \times m$ matrix $\mathbf{A}$ describes electrostatic interaction between $m$ surface charges and the $m \times n \mathbf{B}$ matrix describes the interaction of the surface charges with $n$ atomic charges of the solute. ${ }^{33}$ The GEPOL93 scheme $^{34}$ was used to construct the molecular boundary surface.

The charge on atom $A$ in the excited state $\psi_{i}, q_{A}^{i}$, was calculated as

$$
\mathrm{q}_{\mathrm{A}}^{\mathrm{i}}=\mathrm{q}_{\mathrm{A}}^{0}+\Delta_{\mathrm{A}}^{\mathrm{i}}, \quad \Delta_{\mathrm{A}}^{\mathrm{i}}=\frac{1}{2} \sum_{\mathrm{B} \neq \mathrm{A}} \sum_{\alpha \in \mathrm{A}, \beta \in \mathrm{B}}\left(\mathrm{P}_{\alpha \beta}^{0 \mathrm{i}} \mathrm{P}_{\alpha \beta}^{0 \mathrm{i}}-\mathrm{P}_{\beta \alpha}^{0 \mathrm{i}} \mathrm{P}_{\beta \alpha}^{0 \mathrm{i}}\right),
$$

where $\mathrm{q}_{\mathrm{A}}^{0}$ is the atomic charge on $\mathrm{A}$ in the ground state (the reference state) and $\Delta_{\mathrm{A}}^{\mathrm{i}}$ is its change upon $\psi_{0} \rightarrow \psi_{\mathrm{i}}$ excitation.

The non-equilibrium solvation energy for excited state $\psi_{\mathrm{i}}$ can be estimated as: ${ }^{33,35}$

$$
\mathrm{E}_{\mathrm{S}}^{\mathrm{neq}}\left(\mathrm{Q}^{0}, \Delta, \varepsilon, \mathrm{n}^{2}\right)=f(\varepsilon) \Delta^{+} \mathrm{DQ}^{0}-\frac{1}{2} f\left(\mathrm{n}^{2}\right) \Delta^{+} \mathrm{D} \Delta,
$$

In Eq. (4), $\mathrm{n}^{2}$ (the refraction index squared) is the optical dielectric constant of the medium, the vector $\Delta$ describes the change of electronic density in the molecule by excitation in terms of atomic charges, see Eq. (3).

\section{Electron transfer parameters}

The rate of nonadiabatic electron transfer at the temperature $T$ can be estimated using Marcus equation $^{28}$

$$
k_{c t}=\frac{2 \pi}{\hbar} V_{i j}^{2} \frac{1}{\sqrt{4 \pi \lambda k_{B} T}} \exp \left(-\frac{\left(\lambda+\Delta G^{0}\right)^{2}}{4 \lambda k_{B} T}\right)
$$

Three parameters control the ET rate electronic coupling $V_{i j}$ between the initial and final states, reorganization energy $\lambda$, and the Gibbs energy $\Delta G^{0}$.

In the system $\mathrm{C}_{60} @ \mathrm{C}_{240}$, there are many degenerate and nearly-degenerate states. Consequently, a two-state model that takes into account only one state per each site, cannot appropriately use to describe electronic coupling in the model. On the basis of our analysis of electronic states, several combinations of initial and final states were considered. The Fragment Charge Difference (FCD) ${ }^{36-37}$ were employed to calculate the coupling. 
The reorganization energy is usually divided into two parts, $\lambda=\lambda_{i}+\lambda_{s}$, including the internal and solvent terms, respectively. Often, the term $\lambda_{s}$ is treated classically whereas the internal component is calculated with a quantum-chemical approach. ${ }^{28}$

The internal reorganization energy $\lambda_{i}$ was calculated at the B3LYP/6-31G(d) level. To types of CT states, $\mathrm{C}_{60}{ }^{+} @ \mathrm{C}_{240}{ }^{-}$and $\mathrm{C}_{60}{ }^{-} @ \mathrm{C}_{240}{ }^{+}$, were considered. For the radical cation and radical anion states, the unrestricted Kohn-Sham method was applied. To estimate $\lambda_{i}$ for ET between the sites $\mathrm{A}$ and $\mathrm{B}, \mathrm{AB} \rightarrow \mathrm{A}^{+} \mathrm{B}^{-}$, the following terms were computed : (1) energies of neutral species $\mathrm{A}$ and $\mathrm{B}$ at optimized geometries, $E_{0}(\mathrm{~A})$ and $E_{0}(\mathrm{~B}),(2)$ energies of the corresponding radical ions at optimized geometries, $E_{+}\left(\mathrm{A}^{+}\right)$and $E_{-}\left(\mathrm{B}^{-}\right),(3)$ energies of neutral $\mathrm{A}$ and $\mathrm{B}$, calculated at the geometries of $\mathrm{A}^{+}$and $\mathrm{B}^{-}, E_{+}(\mathrm{A})$ and $E_{-}(\mathrm{B})$, and (4) the energies of the radical ions at the geometries of corresponding neutral molecules $E_{0}\left(\mathrm{~A}^{+}\right)$ and $E_{0}\left(\mathrm{~B}^{-}\right)$. Then $\lambda_{\mathrm{i}}$ is a sum of the reorganization energies of the site $\mathrm{A}$ and $\mathrm{B}$, $\lambda_{\mathrm{i}}=\lambda_{\mathrm{i}}(\mathrm{A})+\lambda_{\mathrm{i}}(\mathrm{B})$ :

$$
\begin{aligned}
& \lambda_{\mathrm{i}}(\mathrm{A})=\frac{1}{2}\left[E_{+}(\mathrm{A})-E_{+}\left(\mathrm{A}^{+}\right)+E_{0}\left(\mathrm{~A}^{+}\right)-E_{0}(\mathrm{~A})\right] \\
& \lambda_{\mathrm{i}}(\mathrm{B})=\frac{1}{2}\left[E_{-}(\mathrm{B})-E_{-}\left(\mathrm{B}^{-}\right)+E_{0}\left(\mathrm{~B}^{-}\right)-E_{0}(\mathrm{~B})\right]
\end{aligned}
$$

Our B3LYP calculations predict that the internal reorganization energy is $0.13 \mathrm{eV}$ for ET from $\mathrm{C}_{60}$ to $\mathrm{C}_{240}$ (formation of $\mathrm{C}_{60}{ }^{+} @ \mathrm{C}_{240}{ }^{-}$) and $0.10 \mathrm{eV}$ for $\mathrm{ET}$ from $\mathrm{C}_{240}$ to $\mathrm{C}_{60}$. The solvent term $\lambda_{\mathrm{s}}$ is determined by the difference of the non-equilibrium and equilibrium solvation energies:

$$
\lambda_{\mathrm{S}}=\mathrm{E}_{\mathrm{S}}^{\mathrm{neq}}\left(\mathrm{Q}^{\mathrm{i}}, \Delta, \varepsilon, \mathrm{n}^{2}\right)-\mathrm{E}_{\mathrm{S}}^{\mathrm{eq}}\left(\mathrm{Q}^{\mathrm{f}}, \varepsilon\right)
$$

where $\Delta=Q^{f}-Q^{i}$, see Eqs (2)-(4). Very small values were found also for $\lambda_{s}$. For the both types of the CS processes $\lambda_{\mathrm{s}}$ is estimated at $0.05 \mathrm{eV}$. Thus the total reorganization energy derived from our calculation is $0.17 \mathrm{eV}$.

\section{Results and Discussion}

In studies of charge transfer processes, adiabatic ionization potentials (IP) and electron affinities (EAs) are two important quantities. For isolated $\mathrm{C}_{60}, \mathrm{~B} 3 \mathrm{LYP} / 6-31 \mathrm{G}^{*}$ yields 7.15 and $2.06 \mathrm{eV}$ (exp. values are $7.58^{38}$ and $2.68^{39} \mathrm{eV}$, whereas previous DFT calculated values gave 7.70 and $2.90 \mathrm{eV}^{23}$ ) for IP and EA, respectively. Differences of about $0.5 \mathrm{eV}$ in

calculated and experimental IPs and EAs are not unusual using DFT methods. ${ }^{40}$ For $\mathrm{C}_{240}$, our calculated IP and EA are 6.81 and $2.70 \mathrm{eV}$ to be compared with previous DFT calculated values of 6.55 and $3.54 \mathrm{eV} .{ }^{23}$ From calculated IPs and EAs of $\mathrm{C}_{60}$ and $\mathrm{C}_{240}$, one can expect 
that ET from $\mathrm{C}_{60}$ to $\mathrm{C}_{240}$ (i. e. $\mathrm{C}_{60}{ }^{+\delta} @ \mathrm{C}_{240}{ }^{-\delta}$ ) is more favorable than that in the opposite direction. However, in the ground state of $\mathrm{C}_{60} @ \mathrm{C}_{240}$, the B3LYP scheme predicts the net charge on $\mathrm{C}_{60}$ and $\mathrm{C}_{240}$ to be -0.049 and +0.049 , respectively. The same character of charge separation, $\mathrm{C}_{60}{ }^{-\delta} @ \mathrm{C}_{240}{ }^{+\delta}$, is found using the INDO/S: the charge on the internal and external fullerenes is -0.144 and $+0.144 \mathrm{e}$, respectively. The charge separation obtained by Grimme et al. ${ }^{19}$ using a Mulliken population analysis with the B97-D/TZV(d,p) functional was in the same direction but much higher (0.67 e).

Figure 2 shows the overall character of the lowest 300 excited states in $\mathrm{C}_{60} @ \mathrm{C}_{240}$ computed with INDO/S. The states are in the energy region of 1.8-3.6 eV (the corresponding wave length interval $\sim 700-350 \mathrm{~nm}$ ). The electronic transitions from the ground state to lower excited states lying up to $2.5 \mathrm{eV}$ are dipole forbidden by symmetry. The situation is similar to that found for $\mathrm{C}_{60}$. In this molecule, the first allowed transition with a relatively large transition dipole moment corresponds to the $1^{1} \mathrm{~T}_{1 \mathrm{u}} \leftarrow 1^{1} \mathrm{~A}_{\mathrm{g}}$ excitation involving the $\mathrm{HOMO} \rightarrow \mathrm{LUMO}+1$ and $\mathrm{HOMO} \rightarrow$ LUMO+3 transitions. ${ }^{41-42}$ Experimentally, this band was assigned by Leach et al. ${ }^{43}$ to a relatively weak but sharp peak near $3.02 \mathrm{eV}$. Our calculations predict high absorption of the complex is predicted to be at 2.5-2.7 eV and 3.0-3.5 eV (upper panel in Fig. 2), i.e., at somewhat lower energy than that observed in $\mathrm{C}_{60}$. Both $\mathrm{C}_{60}$ and $\mathrm{C}_{240}$ absorb light in these regions (see Table 2). Excited states in donor-acceptor complexes can be characterized as LE states (changes in the electron density occur within the donor or acceptor site), CT states (photon absorption leads to electron transfer between the donor and acceptor) or mixed states that include both LE and CT contributions. In $\mathrm{C}_{60} @ \mathrm{C}_{240}$, there are two types of CT states, $\mathrm{C}_{60}{ }^{+} @ \mathrm{C}_{240}{ }^{-}$and $\mathrm{C}_{60}{ }^{-} @ \mathrm{C}_{240}{ }^{+}$. In first case, $\mathrm{C}_{60}$ is electron donor and $\mathrm{C}_{240}$ is electron acceptor, the opposite situation occurs for $\mathrm{C}_{60}{ }^{-} @ \mathrm{C}_{240}{ }^{+}$. The $\mathrm{CT}$ states cannot be directly excited by light absorption because of their weak oscillator strength. However, these states can be populated because of their coupling to strongly absorbing LE states. Our calculation suggests that in $\mathrm{C}_{60} @ \mathrm{C}_{240}$, the $\mathrm{CT}$ states and LE states with the strong oscillator strength lie in same energy region (e.g. at $2.5 \mathrm{eV}$ ), and therefore, even their weak interaction should populate the CT states by light absorption. Figure 3 shows the character of excited states in the system. 

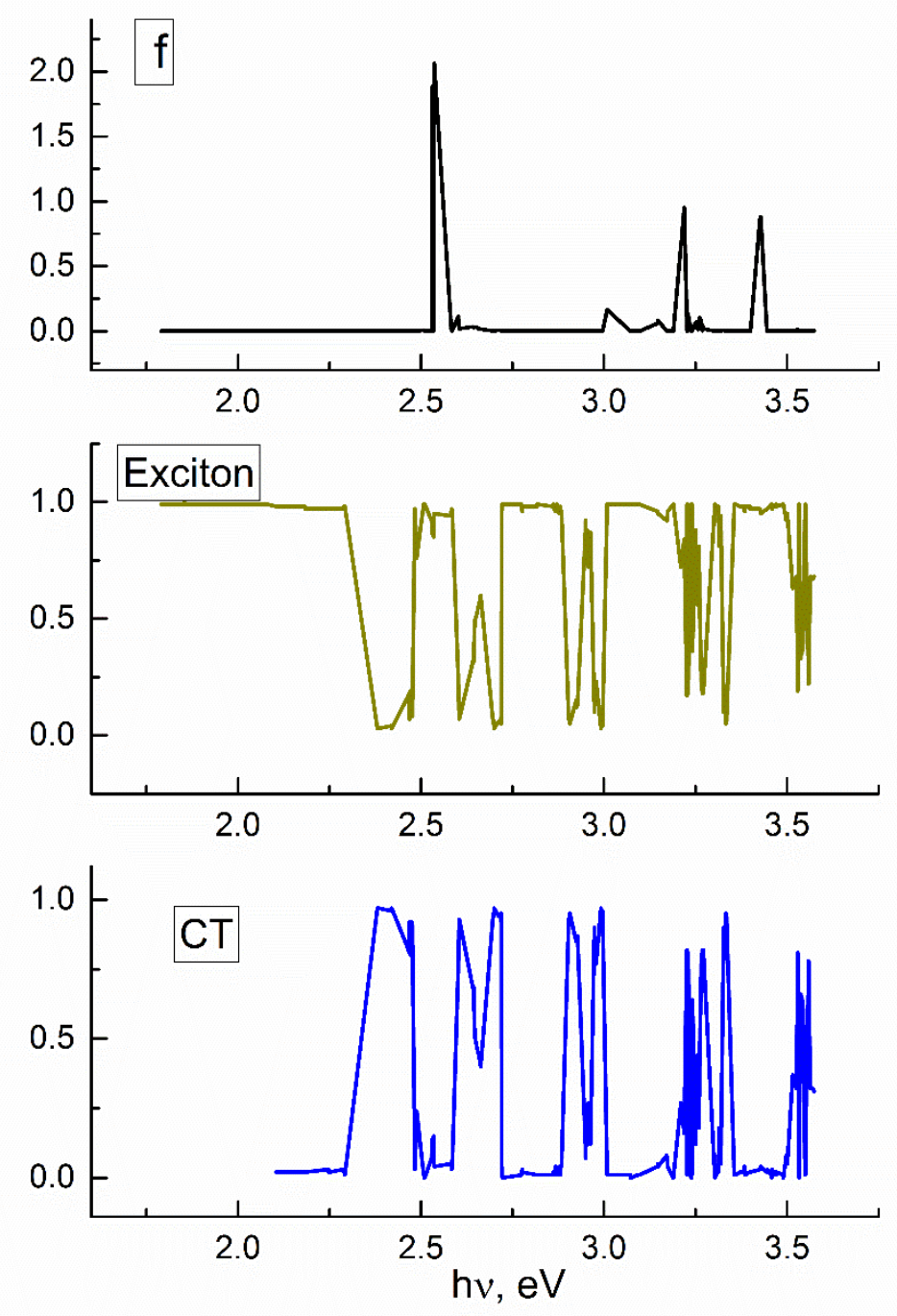

Figure 2. Character of excited states in $\mathrm{C}_{60} @ \mathrm{C}_{240}$. Oscillator strength (upper panel), Contribution of exciton (locally excited) and CT configurations (middle and lower panels).

Note that there is a difference between CT and CS states. The states $\mathrm{A}^{+} \mathrm{B}^{-}$and $\mathrm{A}^{-} \mathrm{B}^{+}$can be referred as both $\mathrm{CS}$ and $\mathrm{CT}$ states. Usually such states have large dipole moments. If the states $\mathrm{A}^{+} \mathrm{B}^{-}$and $\mathrm{A}^{-} \mathrm{B}^{+}$mix, $\Psi_{1,2}=\frac{1}{\sqrt{2}}\left(\psi_{A^{+} B^{-}} \pm \psi_{A^{+} B^{-}}\right)$, the charges on $\mathrm{A}$ and $\mathrm{B}$ in $\Psi_{1}$ and $\Psi_{2}$ are equal to zero. It means that there is no charge separation in the CT states $\Psi_{1}$ and $\Psi_{2}$. Such CT states are difficult to distinguish from LE states and their superposition in systems where molecules A and B have similar electronic properties. For instance in symmetric systems with identical donor and acceptor sites, there is no charge separation in all CT states. 
As seen in Figure 3, the low-lying CT states are CS states $\mathrm{C}_{60}{ }^{+} @ \mathrm{C}_{240^{-}}$, where an electron is transferred from the inner to the outer sphere. The states with the opposite CS character, $\mathrm{C}_{60}{ }^{-} @ \mathrm{C}_{240}{ }^{+}$, are energetically higher and lie at 2.8-3.3 eV. The lowest $\mathrm{C}_{60}{ }^{+} @ \mathrm{C}_{240^{-}}$states are found to be energetically more favorable by $\sim 0.5 \mathrm{eV}$ than the lowest $\mathrm{C}_{60}{ }^{-} @ \mathrm{C}_{240^{+}}$states. Because of the symmetry of the system the dipole moment of both $\mathrm{C}_{60}{ }^{+} @ \mathrm{C}_{240^{-}}$and $\mathrm{C}_{60} 0^{-} @ \mathrm{C}_{240}{ }^{+}$is equal to zero and cannot be used to identify the CS states.

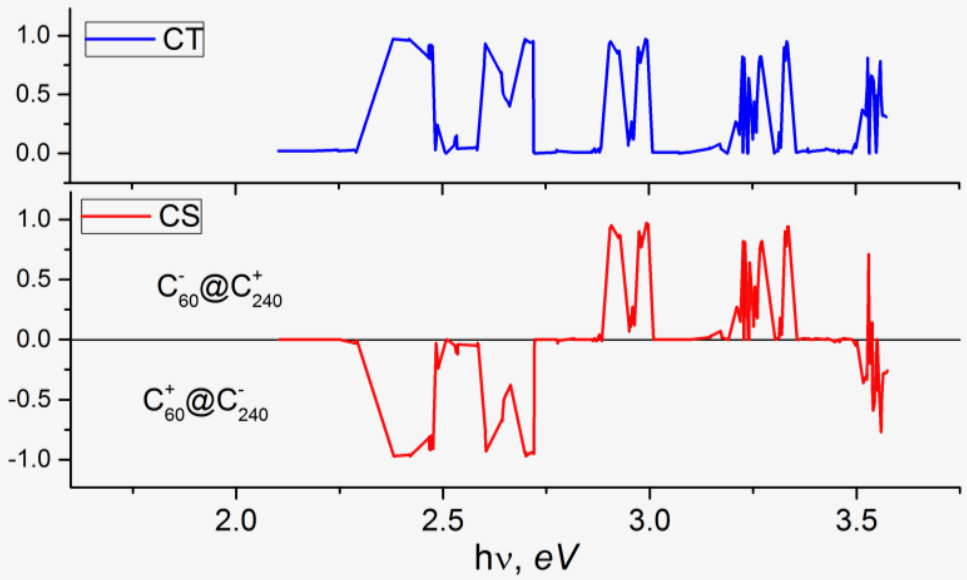

Figure 3. Character of CT states in $\mathrm{C}_{60} @ \mathrm{C}_{240}$.

The electronic properties of the excited states in the range of 1.79-3.00 eV are listed in Table 2. The lowest 22 states are dark (total oscillator strength $<0.001$ ) and localized on the outer sphere; next 10 transition are also dipole forbidden and correspond to local excitations of $\mathrm{C}_{60} .15$ states at 2.38-2.47 eV show significant charge separation, at least 0.97 e is transferred from $\mathrm{C}_{60}$ to $\mathrm{C}_{240}$. A high absorption peak is predicted at $2.53-2.62 \mathrm{eV}$. Electronic transitions localized on both $\mathrm{C}_{240}$ and $\mathrm{C}_{60}$ are responsible for the absorption. These states are followed by $18 \mathrm{CS}$ and 9 mixed LE+CS states with relatively weak absorption ( $\Sigma \mathrm{f}$ 0.03). CS states $\mathrm{C}_{60}{ }^{-} @ \mathrm{C}_{240}{ }^{+}$are found at $2.90 \mathrm{eV}$. Overall, Table 2 demonstrates large variations in the nature of $\sim 150$ excited states lying in the low-energy region of 1.8-3.0 eV. There are several electronic transitions that have a significant CS contribution and relatively strong oscillator strength. Such transitions are responsible for direct generating charge separation $\mathrm{C}_{60}{ }^{+} @ \mathrm{C}_{240}{ }^{-}$by light absorption.

Table 2. Electronic properties of selected excited states in $\mathrm{C}_{60} @ \mathrm{C}_{240}$ derived from INDO/S calculations. $\mathrm{N}$ is the number of states in the energy region and $\Sigma \mathrm{f}$ is the sum of their oscillator strengths. The exciton localization $X$ and charge separation $\Delta q$ are defined by Eq. (1)

\begin{tabular}{lllllll}
\hline $\mathrm{h} v, \mathrm{eV}$ & $\mathrm{N}$ & $\Sigma \mathrm{f}$ & $\mathrm{X}\left(\mathrm{C}_{240}\right)$ & $\mathrm{X}\left(\mathrm{C}_{60}\right)$ & $\Delta \mathrm{q}$ & Description \\
\hline $1.79-2.08$ & 22 & 0.00 & 0.99 & 0.01 & 0.00 & dark LE on $\mathrm{C}_{240}$ \\
$2.10-2.25$ & 10 & 0.00 & 0.01 & 0.98 & 0.01 & dark LE on $\mathrm{C}_{60}$ \\
2.29 & 4 & 0.00 & 0.96 & 0.01 & 0.03 & dark LE on $\mathrm{C}_{240}$
\end{tabular}




\begin{tabular}{|c|c|c|c|c|c|c|}
\hline $2.38-2.47$ & 15 & 0.00 & 0.02 & 0.01 & 0.97 & $\mathrm{CS} \mathrm{C}_{60}{ }^{+} @ \mathrm{C}_{240^{-}}$ \\
\hline $2.48-2.53$ & 15 & 0.00 & 0.76 & 0.01 & 0.22 & $\mathrm{LE}$ and mixed CS \\
\hline $2.53-2.62$ & 15 & 6.08 & & & 0.05 & Large absorption \\
\hline $2.60-2.72$ & 18 & 0.30 & 0.13 & 0.11 & 0.75 & $\mathrm{CS} \mathrm{C}_{60}{ }^{+} @ \mathrm{C}_{240^{-}}$ \\
\hline $2.72-2.88$ & 15 & 0.00 & 0.98 & 0.01 & 0.01 & $\begin{array}{l}\text { Mixed states } \\
\text { dark LE on } C_{240}\end{array}$ \\
\hline $2.86-2.89$ & 9 & 0.00 & 0.24 & 0.73 & 0.03 & dark $\mathrm{LE}$ on $\mathrm{C}_{60}$ \\
\hline $2.90-2.95$ & 6 & 0.00 & 0.07 & 0.00 & 0.93 & $\mathrm{CS} \mathrm{C}_{60}{ }^{-} @ \mathrm{C}_{240}{ }^{+}$ \\
\hline $2.92-2.96$ & 8 & 0.00 & 0.85 & 0.00 & 0.15 & Mixed states \\
\hline $2.97-3.00$ & 9 & 0.00 & 0.10 & 0.00 & 0.90 & $\mathrm{CS} \mathrm{C}_{60}{ }^{-} @ \mathrm{C}_{240^{+}}$ \\
\hline
\end{tabular}

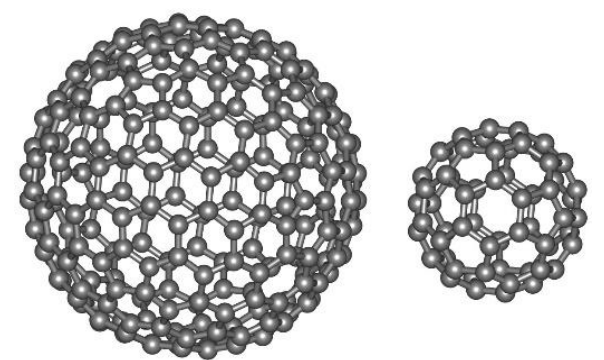

Figure 4. Van der Waals complex $\mathrm{C}_{240} \cdot \mathrm{C}_{60}$

To understand better the electronic features of CNOs let us briefly compare two systems $\mathrm{C}_{60} @ \mathrm{C}_{240}$ and a non-encapsulated van der Waals complex $\mathrm{C}_{240} \cdot \mathrm{C}_{60}$ formed by $\mathrm{C}_{240}$ and $\mathrm{C}_{60}$ (see Fig. 4). The most important difference is that the CS states are stabilized significantly better in $\mathrm{C}_{60} @ \mathrm{C}_{240}$ than in $\mathrm{C}_{240} \cdot \mathrm{C}_{60}$ because of Coulomb interaction between the charged spheres. In $\mathrm{C}_{60} @ \mathrm{C}_{240}$, the $\mathrm{CS}$ states and LE states responsible for the absorption at $2.5 \mathrm{eV}$ are found to be of similar energy. In the non-encapsulated complex $\mathrm{C}_{240} \cdot \mathrm{C}_{60}$, the CS states are $\sim 0.5 \mathrm{eV}$ higher than the LE states. This energy gap makes hinders the photoinduced charge separation in $\mathrm{C}_{60} \cdot \mathrm{C}_{240}$.

Table 3 lists electronic couplings $V_{\mathrm{CR}}$ for charge recombination of the low-energy states $\mathrm{C}_{60}{ }^{-}$ @ $\mathrm{C}_{240}{ }^{+}$(in the course of the process the CS states in the range of 2.38-2.47 eV are converted to the ground state of $\left.\mathrm{C}_{60} @ \mathrm{C}_{240}\right)$. As seen, the $V_{\mathrm{CR}}$ values differ by an order of magnitude. The Gibbs energy of the reactions is $\sim-2.4 \mathrm{eV}$ and the ET occurs in the inverse Marcus regime. Because the decay of a CS state is proportional to $V_{C R}^{2}$, the relative life time for each CS state is assumed to be proportional to $1 / V_{C R}^{2}$. Estimated values of $\tau_{i, \text { rel }}=\tau_{i} / \tau_{1}=V_{1, C R}^{2} / V_{i, C R}^{2}$ are merged in Table 3. The long-living CS states (states 4,3 , and 12) are of special interest. Population of these states is controlled by the electronic coupling square of the CS states and LE states with the strong oscillator strength (at 2.53-2.62 eV). 
The computed coupling $V_{\mathrm{CS}}$ values are listed in Table 4. As seen, the coupling depends strongly on the initial and final states. The largest values of the coupling are found for the states $\mathrm{LE}_{3} \rightarrow \mathrm{CS}_{12}\left(V_{\mathrm{CS}}=0.015 \mathrm{eV}\right)$ and $\mathrm{LE}_{2} \rightarrow \mathrm{CS}_{12}\left(V_{\mathrm{CS}}=0.012 \mathrm{eV}\right)$. The Gibbs energy of the ET processes is ca. $-0.06 \mathrm{eV}$. Using the reorganization energy of $0.17 \mathrm{eV}$ (see the section Methods) we can estimate the absolute rate for the CS processes using Eq. (5): $k_{\mathrm{LE} 3 \rightarrow \mathrm{CS} 12}=$ $4.5 \mathrm{ps}^{-1}$ and $k_{\mathrm{LE} 2 \rightarrow \mathrm{CS} 12}=3.0 \mathrm{ps}^{-1}$.

Table 3. Electronic coupling for charge recombination (in $\mathrm{eV}$ ) and relative lifetime of the CS states

\begin{tabular}{llc}
\hline CS state & $\mid V_{\mathrm{CR} \mid, e V}$ & $\tau_{\mathrm{i}, \mathrm{rel}=\tau_{\mathrm{i}} / \tau_{1}}$ \\
\hline 1 & $0.805 \mathrm{E}-02$ & 1 \\
2 & $0.190 \mathrm{E}-02$ & 18 \\
3 & $0.706 \mathrm{E}-03$ & 130 \\
4 & $0.285 \mathrm{E}-03$ & 798 \\
5 & $0.347 \mathrm{E}-02$ & 5 \\
6 & $0.232 \mathrm{E}-01$ & 0.12 \\
7 & $0.187 \mathrm{E}-01$ & 0.19 \\
8 & $0.111 \mathrm{E}-01$ & 0.53 \\
9 & $0.457 \mathrm{E}-01$ & 0.03 \\
10 & $0.567 \mathrm{E}-01$ & 0.02 \\
11 & $0.174 \mathrm{E}-01$ & 0.21 \\
12 & $0.808 \mathrm{E}-03$ & 99 \\
13 & $0.118 \mathrm{E}-02$ & 47 \\
14 & $0.225 \mathrm{E}-01$ & 0.13 \\
15 & $0.108 \mathrm{E}-01$ & 0.556 \\
\hline
\end{tabular}

Table 4. Electronic coupling of selected CS and LE states in $\mathrm{C}_{60} @ \mathrm{C}_{240}$ (in $\mathrm{eV}$ )

\begin{tabular}{lllll}
\hline CSLLE & $1(\mathrm{f}=1.88)$ & $2(\mathrm{f}=1.22)$ & $3(\mathrm{f}=0.81)$ & $4(\mathrm{f}=2.06)$ \\
\hline 3 & $0.380 \mathrm{E}-03$ & $0.242 \mathrm{E}-03$ & $0.588 \mathrm{E}-03$ & $0.490 \mathrm{E}-04$ \\
4 & $0.120 \mathrm{E}-02$ & $0.289 \mathrm{E}-02$ & $0.359 \mathrm{E}-02$ & $0.365 \mathrm{E}-04$ \\
12 & $0.199 \mathrm{E}-02$ & $0.122 \mathrm{E}-01$ & $0.149 \mathrm{E}-01$ & $0.493 \mathrm{E}-03$ \\
\hline
\end{tabular}

Another interesting point to be mentioned is that the solvation energy of the ground and excited states $\mathrm{C}_{60} @ \mathrm{C}_{240}$ (including CS states) is quite small and only insignificant effects of environment are expected in the electronic spectrum. Even in the limiting case of very polar environment (water, $\varepsilon=80$ ), the solvation energy of the ground state and the CS state $\mathrm{C}_{60}{ }^{+1} @ \mathrm{C}_{240}{ }^{-1}$ is found to be -0.02 and $-0.14 \mathrm{eV}$, respectively. Thus the corresponding shift of the absorption peak is $0.12 \mathrm{eV}$. Normally, the solvent stabilization energy increases 
considerably by passing from the ground (or LE) state to CS states. In particular, the solvent stabilization energy for the GS and CS states of the van-der-Waals complex $\mathrm{C}_{240} \cdot \mathrm{C}_{60}$ is calculated at -0.02 and $-1.24 \mathrm{eV}$. Because of the unique structure of $\mathrm{C}_{60} @ \mathrm{C}_{240}$ where the positive and negative charges are localized on concentric shells, the electrostatic field at the solute-solvent boundary surface remains very weak independent of the amount of charge transferred between the fullerenes. We note an important difference between the $\mathrm{C}_{60} @ \mathrm{C}_{240}$ and symmetric donor-acceptor complexes. In the last case, the solute solvent interactions will strongly stabilize asymmetric CS states $\mathrm{D}^{+} \mathrm{A}^{-}$and $\mathrm{D}^{-} \mathrm{A}^{+}$and the relative position of $\mathrm{LE}$ and CS states of the DA complex should be rather sensitive to the environment polarity.

\section{Conclusions}

Based on the INDO/S calculations we have analyzed the character of excited states in the encapsulated fullerene $\mathrm{C}_{60} @ \mathrm{C}_{240}$ in terms of exciton localization and charge transfer between the inner and outer shells. The structure of $\mathrm{C}_{60} @ \mathrm{C}_{240}$ is found to significantly stabilize charge-separated (CS) states as compared to a non-encapsulated van der Waals complex of the two fullerenes. As a result, the charge-separated states $\mathrm{C}_{60}{ }^{+} @ \mathrm{C}_{240}{ }^{-}$and locally excited strongly absorbing states lie in the same region of the electronic spectrum (2.4-2.6 eV) and can be effectively populated. The CS states $\mathrm{C}_{60}{ }^{-} @ \mathrm{C}_{240}{ }^{+}$lie $\sim 0.5 \mathrm{eV}$ higher in energy than the states $\mathrm{C}_{60}{ }^{+} @ \mathrm{C}_{240}$. The $\mathrm{CT}$ excitation energies are practically independent of the environment polarity, unlike the situation observed for common donor-acceptor systems. An extremely small solvent reorganization energy, $0.05 \mathrm{eV}$, has been found for ET within $\mathrm{C}_{60} @ \mathrm{C}_{240}$ in polar medium. Electronic couplings for photoinduced charge separation and charge recombination processes have been calculated. The absolute rate of the formation of the CS

states $\mathrm{C}_{60}{ }^{+} @ \mathrm{C}_{240}{ }^{-}$have been estimated at $\sim 4 \mathrm{ps}^{-1}$. The unique electronic features found in the molecule $\mathrm{C}_{60} @ \mathrm{C}_{240}$ are likely to be shared by other CNOs.

\section{Acknowledgements}

We are grateful for financial support from the Spanish Ministerio de Economía y Competitividad (MINECO) (Projects CTQ2014-54306-P and CTQ2015-69363-P), the Catalan DIUE (Project 2014SGR931, ICREA Academia 2014 Award to MS, and Xarxa de Referència en Química Teòrica i Computacional), and the FEDER fund (UNGI10-4E-801). 


\section{References}

1. Xu, B.-s., Prospects and Research Progress in Nano Onion-Like Fullerenes. New Carbon Mater. 2008, 23, 289-301.

2. Echegoyen, L.; Ortiz, A. L.; Chaur, M. N.; Palkar, A. J., Carbon Nano Onions. In Chemistry of Nanocarbons, Akasaka, T.; Wudl, F.; Nagase, S., Eds. John Wiley \& Sons: Chichester, 2010.

3. Bartelmess, J.; Giordani, S., Carbon Nano-Onions (Multi-Layer Fullerenes): Chemistry and Applications. Beilstein J. Nanotechnol. 2014, 5, 1980-1998.

4. Iijima, S., Direct Observation of the Tetrahedral Bonding in Graphitized Carbon Black by High Resolution Electron Microscopy. J. Cryst. Growth 1980, 50, 675-683.

5. Kroto, H. W.; Heath, J. R.; O'Brien, S. C.; Curl, R. F.; Smalley, R. E., C60: Buckminsterfullerene. Nature 1985, 318, 162-163.

6. $\quad$ Iijima, S., The 60-Carbon Cluster Has Been Revealed. J. Phys. Chem. 1987, 91, 3466-3467.

7. Ugarte, D., Curling and Closure of Graphitic Networks under Electron-Beam Irradiation. Nature 1992, 359, 707-709.

8. Han, F.-D.; Yao, B.; Bai, Y.-J., Preparation of Carbon Nano-Onions and Their Application as Anode Materials for Rechargeable Lithium-Ion Batteries. J. Phys. Chem. C 2011, 115, 8923-8927.

9. Mordkovich, V. Z.; Shiratori, Y.; Hiraoka, H.; Takeuchi, Y., Synthesis of Multishell Fullerenes by Laser Vaporization of Composite Carbon Targets. Phys. Solid State 2002, 44, 603-606. 10. Georgakilas, V.; Guldi, D. M.; Signorini, R.; Bozio, R.; Prato, M., Organic Functionalization and Optical Properties of Carbon Onions. J. Am. Chem. Soc. 2003, 125, 14268-14269.

11. Pech, D.; Brunet, M.; Durou, H.; Huang, P.; Mochalin, V.; Gogotsi, Y.; Taberna, P.-L.; Simon, P., Ultrahigh-Power Micrometre-Sized Supercapacitors Based on Onion-Like Carbon. Nat. Nanotechnol. 2010, 5, 651-654.

12. Xu, B.; Yang, X.; Wang, X.; Guo, J.; Liu, X., A Novel Catalyst Support for DMFC: OnionLike Fullerenes. J. Power Sources 2006, 162, 160-164.

13. Hirata, A.; Igarashi, M.; Kaito, T., Study on Solid Lubricant Properties of Carbon Onions Produced by Heat Treatment of Diamond Clusters or Particles. Tribol. Int. 2004, 37, 899-905.

14. Keller, N.; Maksimova, N. I.; Roddatis, V. V.; Schur, M.; Mestl, G.; Butenko, Y. V.; Kuznetsov, V. L.; Schlögl, R., The Catalytic Use of Onion-Like Carbon Materials for Styrene Synthesis by Oxidative Dehydrogenation of Ethylbenzene. Angew. Chem. Int. Ed. 2002, 41, 18851888.

15. Koudoumas, E.; Kokkinaki, O.; Konstantaki, M.; Couris, S.; Korovin, S.; Detkov, P.; Kuznetsov, V.; Pimenov, S.; Pustovoi, V., Onion-Like Carbon and Diamond Nanoparticles for Optical Limiting. Chem. Phys. Lett. 2002, 357, 336-340.

16. Mordkovich, V. Z., The Observation of Large Concentric Shell Fullerenes and FullereneLike Nanoparticles in Laser Pyrolysis Carbon Blacks. Chem. Mater. 2000, 12, 2813-2818.

17. Diez, R. P.; Iñtiguez, M. P., Density Functional Study of the Intershell Interaction Energy in Carbon Onions. Int. J. Quantum Chem 1995, 56, 689-696.

18. Casella, G.; Bagno, A.; Saielli, G., Spectroscopic Signatures of the Carbon Buckyonions $\mathrm{C}_{60} @ \mathrm{C}_{180}$ and $\mathrm{C}_{60} @ \mathrm{C}_{240}$ : A Dispersion-Corrected DFT Study. Phys. Chem. Chem. Phys. 2013, 15, 18030-18038.

19. Grimme, S.; Mück-Lichtenfeld, C.; Antony, J., Noncovalent Interactions between Graphene Sheets and in Multishell (Hyper)Fullerenes. J. Phys. Chem. C 2007, 111, 11199-11207.

20. Zope, R. R., Electronic Structure and Static Dipole Polarizability of $\mathrm{C}_{60} @ \mathrm{C}_{240}$. J. Phys. B: At. Mol. Opt. Phys. 2008, 41, 085101.

21. Zope, R. R.; Bhusal, S.; Basurto, L.; Baruah, T.; Jackson, K., Site Specific Atomic Polarizabilities in Endohedral Fullerenes and Carbon Onions. J. Chem. Phys. 2015, 143, 084306.

22. Tarento, R. J.; Joyes, P., Size Dependence of the Electronic and Magnetic Properties of Fullerenes $\left(\mathrm{C}_{60}-\mathrm{C}_{240}\right)$. Z. Phys. D 1996, 37, 165-167. 
23. Lewis, G. R.; Bunting, W. E.; Zope, R. R.; Dunlap, B. I.; Ellenbogen, J. C., Smooth Scaling of Valence Electronic Properties in Fullerenes: From One Carbon Atom, to $\mathrm{C}_{60}$, to Graphene. Phys. Rev. A 2013, 87, 052515.

24. Dolmatov, V. K.; Keating, D. A., Xe 4d Photoionization in $\mathrm{Xe}_{\mathrm{C}} \mathrm{C}_{60}, \mathrm{Xe} @ \mathrm{C}_{240}$, and Xe@C $60 @ \mathrm{C}_{240 .} . J$. Phys.: Conf. Ser. 2012, 388, 022097.

25. Luzanov, A. V.; Zhikol, O. A., Electron Invariants and Excited State Structural Analysis for Electronic Transitions within Cis, Rpa, and Tddft Models. Int. J. Quantum Chem 2010, 110, 902-924.

26. Plasser, F.; Lischka, H., Analysis of Excitonic and Charge Transfer Interactions from Quantum Chemical Calculations. J. Chem. Theory Comput. 2012, 8, 2777-2789.

27. Plasser, F.; Baeppler, S. A.; Wormit, M.; Dreuw, A., New Tools for the Systematic Analysis and Visualization of Electronic Excitations. Ii. Applications. J. Chem. Phys. 2014, 141, 024107.

28. Marcus, R. A.; Sutin, N., Electron Transfers in Chemistry and Biology. Biochim. Biophys. Acta 1985, 811, 265-322.

29. Frisch, M. J., et al. Gaussian 09, Revision D.01, Gaussian, Inc.: Wallingford CT, 2013.

30. Ridley, J.; Zerner, M., Intermediate Neglect of Differential Overlap Technique for Spectroscopy - Pyrrole and Azines. Theor. Chim. Acta 1973, 32, 111-134.

31. Voityuk, A. A., Intermediate Neglect of Differential Overlap for Spectroscopy. WIRES Comp. Mol. Sci. 2013, 3, 515-527.

32. Bauernschmitt, R.; Ahlrichs, R.; Hennrich, F. H.; Kappes, M. M., Experiment Versus Time Dependent Density Functional Theory Prediction of Fullerene Electronic Absorption. J. Am. Chem. Soc. 1998, 120, 5052-5059.

33. Tomasi, J.; Mennucci, B.; Cammi, R., Quantum Mechanical Continuum Solvation Models. Chem. Rev. 2005, 105, 2999-3093.

34. Pascual-Ahuir, J. L.; Silla, E.; Tuñon, I., Gepol - an Improved Description of MolecularSurfaces .3. A New Algorithm for the Computation of a Solvent-Excluding Surface. J. Comput. Chem. 1994, 15, 1127-1138.

35. Klamt, A., Calculation of Uv/Vis Spectra in Solution. J. Phys. Chem. 1996, 100, 3349-3353.

36. Voityuk, A. A.; Rösch, N., Fragment Charge Difference Method for Estimating DonorAcceptor Electronic Coupling: Application to DNA П-Stacks. J. Chem. Phys. 2002, 117, 5607-5616. 37. Voityuk, A. A., Electronic Coupling for Charge Transfer in Donor-Bridge-Acceptor Systems. Performance of the Two-State FCD Model. Phys. Chem. Chem. Phys. 2012, 14, 13789-13793.

38. de Vries, J.; Steger, H.; Kamke, B.; Menzel, C.; Weisser, B.; Kamke, W.; Hertel, I. V., SinglePhoton Ionization of $\mathrm{C}_{60^{-}}$and $\mathrm{C}_{70}$-Fullerene with Synchrotron Radiation: Determination of the Ionization Potential of $\mathrm{C}_{60}$. Chem. Phys. Lett. 1992, 188, 159-162.

39. Huang, D.-L.; Dau, P. D.; Liu, H.-T.; Wang, L.-S., High-Resolution Photoelectron Imaging of Cold $\mathrm{C}_{60}{ }^{-}$Anions and Accurate Determination of the Electron Affinity of $\mathrm{C}_{60}$. J. Chem. Phys. 2014, $140,224315$.

40. Zhan, C.-G.; Nichols, J. A.; Dixon, D. A., Ionization Potential, Electron Affinity, Electronegativity, Hardness, and Electron Excitation Energy: Molecular Properties from Density Functional Theory Orbital Energies. J. Phys. Chem. A 2003, 107, 4184-4195.

41. Hara, T.; Narita, S.; Kumei, S.; Shibuya, T.-i., Complete Tda and Rpa Calculations on the Electronic Transitions of Fullerene- $\mathrm{C}_{60}$ in the $\mathrm{Cndo} / \mathrm{S}$ and Indo/S Approximations. Int. J. Quantum Chem. 2001, 85, 136-161.

42. Hara, T.; Nomura, Y.; Narita, S.; Ito, H.; Shibuya, T.-i., Electric-Dipole Forbidden Transitions in $\mathrm{C}_{60}$ : Oscillator Strengths Induced by the Spin-Orbit Coupling. J. Mol. Struct. Theochem 2002, 589-590, 139-145.

43. Leach, S.; Vervloet, M.; Desprès, A.; Bréheret, E.; Hare, J. P.; John Dennis, T.; Kroto, H. W.; Taylor, R.; Walton, D. R. M., Electronic Spectra and Transitions of the Fullerene $\mathrm{C}_{60}$. Chem. Phys. 1992, 160, 451-466. 


\section{Graphical abstract}

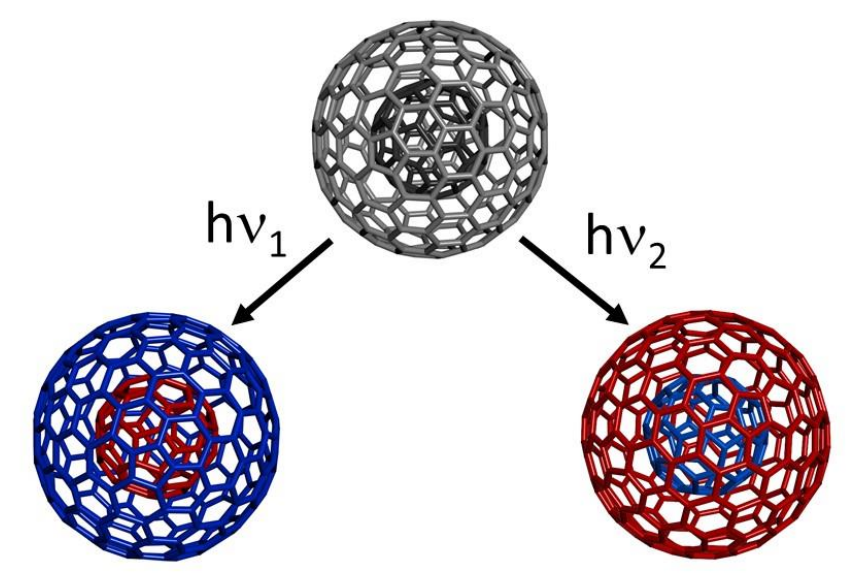

